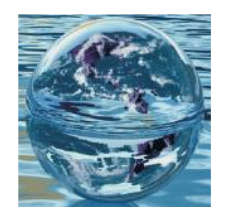

Journal homepage: www. fia.usv.rolfiajournal

Journal of Faculty of Food Engineering,

Ştefan cel Mare University of Suceava, Romania

Volume XX, Issue 2 - 2021, pag. $160-164$

\title{
CLEANING THE VEGETABLE OIL PRODUCTION WASTEWATER
}

\section{WITH ANTHRACITE}

\author{
Sergiy BORUK ${ }^{1}$, Igor WINKLER ${ }^{2 *}$, Vitaliy MISCHENCHUK ${ }^{2}$ \\ ${ }^{1}$ Department of Chemical Analysis, Food Safety and Testing, Institute of Biology, Chemistry and Bioresources, \\ Yu. Fedkovych National University of Chernivtsi, 2 Kotsyubynsky St., Chernivtsi, 58012, Ukraine \\ ${ }^{2}$ Department of Medicinal and Pharmaceutical Chemistry, Bucovina State Medical University, 2 Teatralna Sq., \\ Chernivtsi, 58002,Ukrainewinkler@bsmu.edu.ua \\ *Corresponding author \\ Received $10^{\text {th }}$ May 2021, accepted $28^{\text {th }}$ June 2021
}

\begin{abstract}
The efficiency of anthracite treatment of the wastewaters formed at the sunflower oil production is investigated and discussed in comparison with other water cleaning technologies. It is found that a comparatively small amount of anthracite (10-15\% of the wastewater mass) ensures efficient decontamination and eliminates up to $70 \%$ of the wastewater pollutants. This method does not require any extensive changes in the production technology and can easily be incorporated at the existing production facilities. This efficiency is based on the double-nature structure of the anthracite surface, consisting of the hydrophilic and hydrophobic areas. The former ones ensure a high wettability of the adsorbent and the release of some inorganic ions that provide coagulation of the emulsified contaminants. The latter ones ensure adsorption and extraction of the dissolved and emulsified organic pollutants of the wastewater.

The used adsorbent can be filtered out after the extraction and then disposed of in an environmentally safe way through incineration as an admixture to the regular coal fuel.
\end{abstract}

Keywords: sunflower oil production; wastewater decontamination; porous coal adsorbents; environment protection

\section{Introduction}

Food processing is one of the leading branches of the economy in many countries, including Ukraine. It produces numerous items with stable high market demand and under competitive conditions. Production of vegetable oil (mostly sunflower) is a highly developed part of the food processing in Ukraine, with a total of 6.8 million tons of crude vegetable (mostly sunflower) oil produced in 2019 and 6.1 million tons exported to many countries in Europe and worldwide [1]. It makes Ukraine the world top exporter of these goods [2]. Hence, this branch seems very important for the national economy, and the intense functioning of the oil produc- tion facilities affects environmental conditions in all regions of Ukraine.

The equipment used at many oilproduction facilities is quite outdated, causing an increased level of environmental contamination affecting air, water and soils. In the context of water contamination, it should be understood that any oil production facility generates a wide range of contamination agents at all technological stages [3-6]. The suspended tissues of sunflower seeds and oil emulsions are the main water pollution agents generated at such factories. If not extracted or decontaminated, they cause significant water pollution during the processes of their natural decay. It should also be emphasized that some volatile sulfur compounds are 
formed and released into the atmosphere during these processes. It expands the dangerous environmental effects of the oil production industry beyond the area of water pollution.

Many approaches are applied to oil production wastewater decontamination. The simplest one assumes keeping the wastewaters in an isolated pond until the natural decay processes completed, followed by their gradual discharge into local water bodies. It is an extremely inefficient method that requires a long time and does not ensure sufficient decontamination efficiency. Moreover, it does not control the release of environmentally dangerous volatile decay products into the atmosphere.

Simple filtration, adsorption, electrofiltration, forced oxidation and some other technologies are tested and used widely to increase the efficiency of the oil-production wastewater treatment [4-9]. It should be emphasized that some porous wastes or byproducts of the coal refinery are considered as promising adsorbents for such technologies $[5,7]$. Based on the nature and properties of the water pollution agents present in this type of wastewater, it is expected that adsorbents with hydrophobic or mosaic surface structure should exhibit a comparatively high pollution extraction activity. It is known that coal-like materials are among such adsorbents [5-7, 10], and therefore, their adsorption performance should be investigated to address the above mentioned issue.

In this paper, the results of the oilproduction wastewater treatment by anthracite are reported. This coal material is abundant in Ukraine, comparatively inexpensive and easily available. Besides, it is environmentally neutral and does not generate any secondary water contamination if used for its treatment. Moreover, anthracite can be utilized safely through incineration as a component of the boiler feeding coal mixtures. The wastewater pollution components adsorbed on its surface are organic compounds, and they will also decompose in an environmentally safe way at such incineration.

\section{Experimental}

The following types of wastewaters formed at the sunflower oil production factory in Chernivtsi, Ukraine were used in this investigation:

Series 1: wastewaters formed at the sunflower seeds grinding;

Series 2: wastewaters formed at the evaporation of sunflower oil production sludge.

The "A" brand Ukrainian anthracite with an average ash content of $5.4 \%$ and the moisture content of $2.1 \%$ was used as an adsorbent. The material was ground, and then the 100-250 $\mu \mathrm{m}$ fraction was separated using the appropriate sieves and used in the follow-up adsorption experiments.

Chemical oxygen demand (COD) was determined by the simplified procedure [11] and used as a characteristic of wastewater contamination because the oxidizable organic components are the most common pollutants of this type of wastewater [4]. Besides, the absorbance of the wastewater samples against distilled water was also measured as this parameter depends on the content of the genuinely dissolved or colloid pollutants, not the coarse-dispersed particles. Both water quality parameters were determined for the untreated source samples and the same samples after the anthracite treatment.

The treatment was performed according to the following procedure.

$0.5,1,2,3,4$ or $5 \mathrm{~g}$ of the ground anthracite powder were added to $25 \mathrm{~mL}$ of the wastewater and left for $24 \mathrm{~h}$. Then the suspension was filtered through the paper filter to separate the anthracite adsorbent from water, and the COD index was determined for the filtrates. A control experiment required for the correct COD determination has been performed by the same 
procedure but with the distilled water sample.

\section{Results and discussion}

A high level of contamination was determined in the initial water samples, and their COD indexes were $2450 \mathrm{mg} \mathrm{O} / \mathrm{L}$ and $620 \mathrm{mg} \mathrm{O} / \mathrm{L}$ for series 1 and 2 correspondingly. The absorbance values were comparatively low $(0.32$ and 0.14 , respectively), which means that contamination agents were mostly dissolved or formed stable emulsions. In the case of sample 1 , the distinct smell of hydrogen sulfide, manifesting decomposition of the organic pollutants, appeared in two weeks, while for sample 2, it appeared only in four weeks. In our opinion, this difference is caused by the lower contamination of sample 2 and the presence of some trace quantities of the technological gasoline extractant. It acts as a preservative and decelerates the natural bio-decomposition of the organics. The absorbance of both samples increases to 0.72 (sample 1) and 0.45 (sample 2), while their COD indexes decrease to 1920 and $400 \mathrm{mg} \mathrm{O} / \mathrm{L}$ correspondingly. It can be interpreted as a result of the natural decomposition of the organic substances present in the wastewater samples, which forms the volatile smelling compound leaving the liquid phase.

When the anthracite extractant was applied, COD indexes and absorbance of the filtered samples were decreasing substantially because of intense capturing of the oil contaminants on its surface. The dependencies of these parameters on the amount of anthracite are shown in Figures 1 and 2.

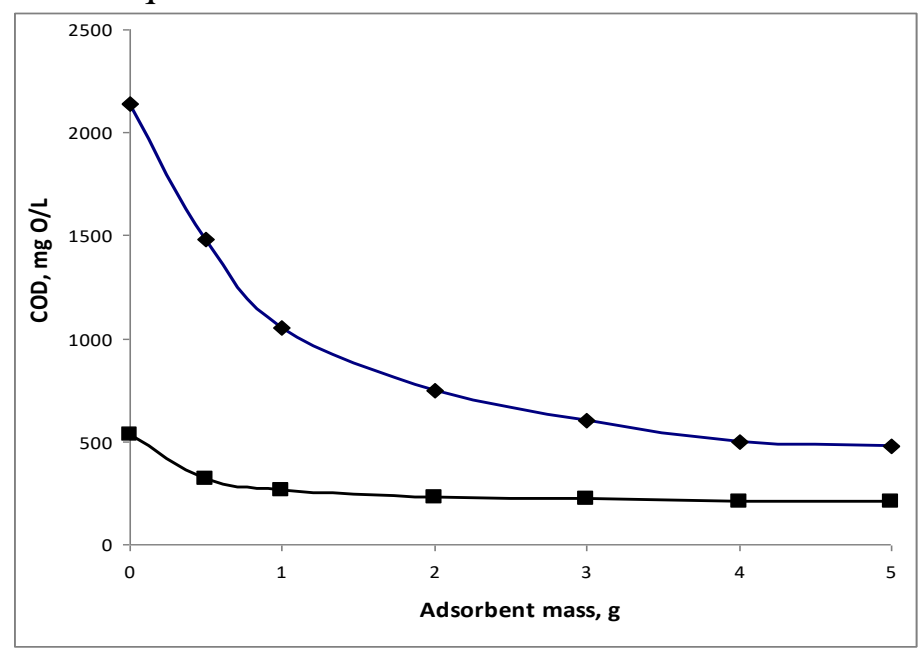

Fig. 1. Dependence of COD indexes on the mass of anthracite added for extraction. $\checkmark$ - sample 1; - - sample 2.

It can be seen that even in the case of highly contaminated sample 1, 3-4 g of anthracite (10-15 wt \% from the sample mass) ensure effective decontamination of the sample (elimination of around $70 \%$ of the pollution agents), while in the case of less contaminated sample 2, this effect is reached even for 1-2 g (5-10\%) of the added anthracite. Similar results can also be seen for the absorbance of the samples (see Fig. 2).
Further increase in the adsorbent mass does not result in the corresponding increase in the cleaning efficiency. Therefore, it can be concluded that $15 \%$ or $10 \%$ of anthracite added to the more or less contaminated samples of the oil-processing wastewaters correspondingly, ensure their efficient decontamination. COD decreases fourfold in the case of more contaminated water, and it halves for less polluted water. It is a promising result that can be achieved

Sergiy BORUK, Igor WINKLER, Vitaliy MISCHENCHUK, Cleaning the vegetable oil production wastewater with anthracite, Food and Environment Safety, Volume XX, Issue 2-2021, pag. 160 - 164 
without any additional investment and by using cheap and abundant material. It should also be emphasized that the used anthracite forms a slurry layer on the bottom of the decontamination pond, and this sediment can easily be dried through the periodical draining of the ponds followed by collecting the dried slurry and burning as a fuel admixture it in the regular coal boilers [12-14]. It should also be noted that this process is environmentally friendly and does not result in any significant increase in dangerous gases emissions [15]. The ash formed after such combustion is similar to the conventional coal ash and can be disposed of similarly.

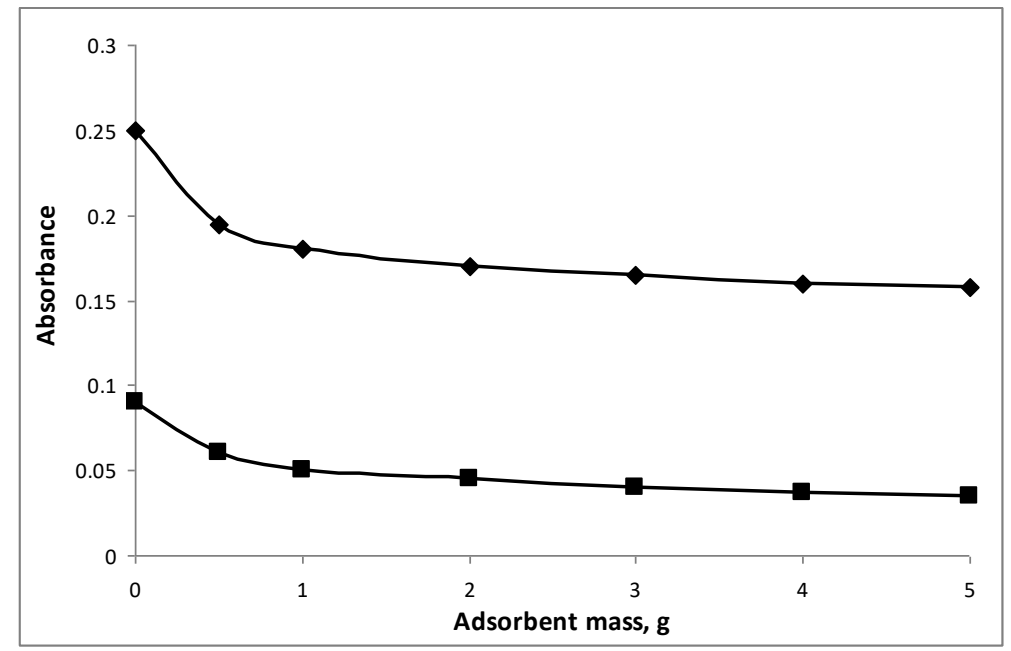

Fig. 2. Dependence of the wastewater absorbance on the mass of anthracite added for extraction. $\checkmark-$ sample 1; - - sample 2.

Based on the registered decrease in the wastewater absorbance after its treatment with anthracite, it can be assumed that this material also provides an additional water cleaning effect by releasing the ions followed by the coagulation of the colloid pollutants present in the water. The visual turbidity of both water samples increased after the anthracite was added, and then the coagulated particles were captured by the adsorbent resulting in a decrease in the turbidity (see Fig. 2). This result is confirmed by an increase in the wastewater samples conductivity after their treatment with anthracite (see Fig. 3).

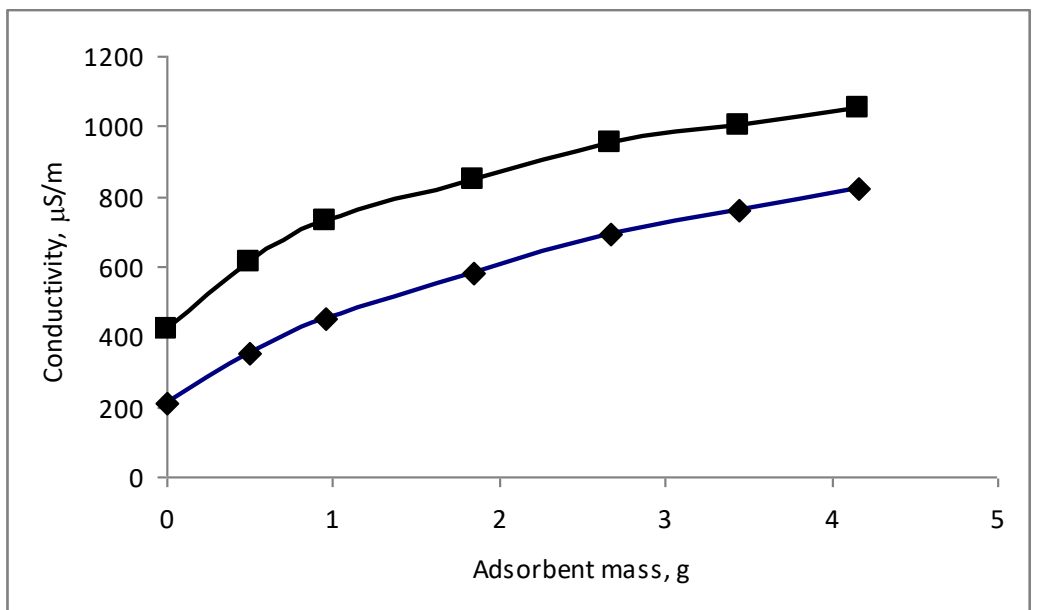

Fig. 3. Dependence of the wastewater conductivity on the mass of anthracite added for extraction. $\checkmark$ - sample 1; $\mathbf{-}$ - sample 2 .

Sergiy BORUK, Igor WINKLER, Vitaliy MISCHENCHUK, Cleaning the vegetable oil production wastewater with anthracite, Food and Environment Safety, Volume XX, Issue 2 - 2021, pag. 160 - 164 


\section{Conclusion}

Anthracite, as an adsorbent with the mosaic surface, captures and eliminates up to 70 $\%$ of the water contaminants present in the wastewaters formed at the sunflower oil production. This efficiency is based on the synergetic effect of the mineral hydrophilic and coal-like hydrophobic surface domains of the anthracite. Due to this surface structure, the anthracite can be added to the wastewater, extract its pollutants, and then be separated by coagulation followed by filtration of the sediment. This technological operation can be performed periodically as the wastewater treatment ponds are filled. Even in the case of the highly polluted sunflower grinding wastewater, 1015 mass $\%$ of anthracite ensure the abovementioned decontamination efficiency.

After the adsorption, the used anthracite can be utilized in an environmentally safe way through its incineration as an admixture to the regular coal fuel.

\section{References}

[1]. Output of some types of industrial products in Ukraine in 2011-2019. State Statistics Service of Ukraine.

http://www.ukrstat.gov.ua/operativ/operativ2006/pr /prm_ric/xls/vppv_2011_2019.xls (Accessed on March 02, 2021).

[2]. V. SHYSHKIN, O. ONYSCHENKO, Present state and prospects of agricultural development of Ukraine, Management and Entrepreneurship: Trends of Development, 3(13), 72-86 (2020). DOI: 10.26661/2522-1566/2020-3/13-06 .

[3]. B. MOSS, Water pollution by agriculture, Phil. Trans. R. Soc. B, 363, 659-666 (2007). DOI: 10.1098/rstb.2007.2176.

[4]. S SHARMA, A. AYGUN, H. SIMSEK, Electrochemical treatment of sunflower oil refinery wastewater and optimization of the parameters us- ing response surface methodology, Chemosphere, 249, $126511 \quad$ (2020). DOI: 10.1016/j.chemosphere.2020.126511.

[5]. S. V. SVERGUZOVA et al, Extracting vegetable oils from model waters by sorbent on the base on carbonate sludge. IOP Conf. Ser.: Earth Environ. Sci., 579, 012042 (2020). DOI: 10.1088/17551315/579/1/012042.

[6]. V. R. VODYANKA et al, The use of thiosemicarbazyde in the pressure-driven processes of wastewater treatment, J. Water Chem. \& Tech., 33(3), 196-201 (2011).

[7]. A. S. MAKAROV et al, Utilization of industrial wastewater in production of coal-water fuel, $J$. Water Chem. \& Tech., 36(4), 180-183 (2014).

[8]. M.A. De La RUBIA, F. RAPOSO, B. RINCON, R. BORJA, Evaluation of the hydrolyticacidogenic step of a two-stage mesophilic anaerobic digestion process of sunflower oil cake, Biores. Tech., 100(18), 4133-4138 (2009). DOI: 10.1016/j.biortech.2009.04.001.

[9]. Y. SAATCI, E. I. ARSALAN, V. KONAR, Removal of total lipids and fatty acids from sunflower oil factory effluent by UASB reactor, Biores. Tech., 87(3), 269-272 (2003). DOI: 10.1016/S0960-8524(02)00255-9.

[10]. A. V. ARTEMOV, A. V. PINKIN, Sorption technologies for cleaning the oil contaminated water, Water: Chem. \& Ecol., 1(1), 19-25 (2008).

[11]. Y. AVSAR, U. KURT, T. GONULLU, Comparison of classical chemical and electrochemical processes for treating rose processing wastewater, J. Hazard. Mater., 148(1-2), 340-345 (2007).

[12]. B. G. MILLER, Coal-water slurry fuel utilization in utility and industrial boilers, Chem. Eng. Progr., 85(3), 29-38 (1989).

[13]. D. O. GLUSHKOV, P. A. STRIZHAK, M. Yu. CHERNETSKII, Organic coal-water fuel: problems and advances (review), Therm. Eng., 63, 707-717 (2016).

[14]. Z. MENG et al., Effect of coal slime on the slurry ability of a semi-coke water slurry, Powder Tech., 359, 261-267 (2020).

[15]. G. S. NYASHINA, P. A. STRIZHAK, The influence of liquid plant additives on the anthropogenic gas emission from the combustion of coal-water slurries, Env. Pollut., 242A, 31-41 (2018). 